\title{
REGULAÇÃO CONTÁBIL E A DIVULGAÇÃO DE INFORMAÇÕES DE OPERAÇÕES COM INSTRUMENTOS FINANCEIROS DERIVATIVOS: ANÁLISE DO IMPACTO DA CVM No 566/08 E DA CVM No 475/08 NO DISCLOSURE DAS COMPANHIAS ABERTAS NO BRASIL
}

\section{ACCOUNTING REGULATION AND DISCLOSURE OF OPERATIONAL INFORMATION USING DERIVATIVE FINANCIAL INSTRUMENTS: AN ANALYSIS OF CVM N. 566/08 AND CVM N. 475/08 IMPACT ON BRAZILIAN OPEN COMPANIES DISCLOSURE}

\author{
FERNANDO DAL-RI MURCIA \\ Doutorando em Controladoria e Contabilidade na \\ Universidade de São Paulo \\ São Paulo/SP, Brasil \\ E-mail: murcia@usp.br
}

\author{
ARIOVALDO DOS SANTOS \\ Livre-Docente pela Universidade de São Paulo \\ Professor Titular da Faculdade de Economia, Administração e \\ Contabilidade da Universidade de São Paulo \\ São Paulo/SP, Brasil \\ E-mail: arisanto@usp.br
}

\section{Resumo}

O objetivo do presente trabalho é analisar o impacto da Deliberação CVM n ${ }^{\circ}$. 566/08 e da Instrução CVM $n^{\circ}$. 475/08 no disclosure de informações de operações com instrumentos financeiros derivativos das companhias abertas no Brasil. Para isso, elaborou-se uma métrica com bases nessas normas, composta por quatro categorias e 22 subcategorias: informações qualitativas (5), informações quantitativas (6), valores dos derivativos (5) e análise de sensibilidade (6). Por meio da técnica de análise de conteúdo, buscou-se analisar as demonstrações contábeis das empresas no exercício findo em 2007, antes da aprovação das referidas normas, e também no exercício findo em 2008 , após a aprovação das mesmas. A idéia subjacente foi justamente comparar o nível de divulgação de informações de operações com instrumentos financeiros derivativos ex ante e ex post. A amostra é composta pelas maiores empresas não-financeiras, listadas na Bolsa de Valores de São Paulo. Dentre os principais resultados da pesquisa destacam-se: (i) dez empresas não fizeram qualquer menção acerca da utilização de derivativos em nota explicativa em 2007; (ii) menos de 50\% das empresas divulgaram aos usuários os efeitos da adoção inicial da CVM nº. 566; (iii) o quadro de análise de sensibilidade não foi evidenciado por qualquer empresa em 2007, sendo que em contrapartida, 90\% das empresas analisadas o evidenciaram em 2008; (iv) a maioria da empresas divulgou o valor justo dos seus derivativos, mas apenas 33,33\% divulgaram os critérios de avaliação e mensuração utilizados para computo desses valores no ano de 2008 . Conclui-se que houve uma melhora no disclosure das empresas, mas ressalta-se que as empresas ainda não divulgam integralmente todas as informações exigidas pelas normas.

Palavras-chave: regulação contábil; instrumentos financeiros derivativos; divulgação de informações.

\begin{abstract}
The objective of this paper is to analyze the impact of CVM 566/08 Deliberation and CVM 475/08 Instruction on the disclosure of information of operations with derivative financial instruments of open capital Brazilian companies. To do so, a measure based on these rules was elaborated. This measure was composed by four categories and 22 subcategories: qualitative information (5), quantitative information (6), derivatives values (5) and sensitiveness analysis (6). Through the content analysis technique, we seek to analyze the accounting demonstrations from companies on the year 2007, before the approval of the rules, and on 2008, after the approval of the rules. The idea was to compare the level of disclosure of the operational information of derivative financial instruments ex ante and ex post. The sample is composed by the larger non-financial companies listed by BOVESPA - São Paulo Stock Market. Among the main results, it is possible to highlight: (i) tem companies did not mention derivatives on their 2007 Notes; (ii) less than $50 \%$ of the companies published to their users the effects of the initial CVM 566 adoption; (iii) the analysis of sensitiveness board was evident by none of the companies on 2007, but evidenced by $90 \%$ of them on the year 2008; (iv) the most part of the companies divulged the fair value of their derivatives, but only $33,33 \%$ of them showed the evaluation criteria and the measurement used to calculate these values on 2008. The conclusion is that there had been an improvement on companies' disclosure, although they do not divulge the information demanded by the rules integrally.
\end{abstract}

Key words: accounting regulation, derivative financial instruments, disclosure. 


\section{INTRODUÇÃO}

Em 17 de dezembro de 2008, a Comissão de Valores Mobiliários (CVM) aprovou duas novas normas que dizem respeito ao reconhecimento, mensuração e disclosure das operações com instrumentos financeiros: a Deliberação CVM $\mathrm{n}^{\circ} . \mathrm{n}^{\circ}$. 566, que aprovou 0 pronunciamento técnico CPC 14 do Comitê de Pronunciamentos Contábeis, e a Instrução CVM nº. 475, que revogou a antiga Instrução CVM nº. 235/95.

Como ambas as normas entraram em vigor no momento de sua publicação, as companhias abertas tiveram que se adequar já no exercício findo em 2008, de modo que os balanços publicados em 2009 já apresentassem os ajustes referentes às operações com instrumentos financeiros.

Mas, especificamente em relação aos instrumentos financeiros derivativos, qual foi o impacto real dessas novas normas nos balanços das empresas? Será que as empresas atenderam às exigências da CVM? Será que o nível de disclosure melhorou? Se sim, em relação a quais tipos de informação?

Dentro desse cenário, o presente trabalho objetiva analisar o impacto da Deliberação CVM n'. 566/08 e da Instrução CVM n. 475/08 no disclosure de informações de operações com instrumentos financeiros derivativos das companhias abertas no Brasil. Para isso, buscou-se analisar os balanços das empresas no exercício findo em 2007, antes da aprovação das referidas normas, e também no exercício findo em 2008, após a aprovação das mesmas. A ideia subjacente foi justamente comparar o nível de divulgação de informações acerca de operações com instrumentos financeiros derivativos ex ante e ex post, de modo a verificar o impacto que as novas normas contábeis tiveram no disclosure das empresas.

A principal motivação para condução dessa pesquisa decorre do fato de que a prática contábil nem sempre é determinada pela normatização, pois a execução da contabilidade tende a ser mais detalhada e complexa do que as normas e nem sempre as empresas implementam as mesmas (BALL; KOTHARI; ROBIN, 2000).

Do mesmo modo, o tema desse trabalho - os instrumentos financeiros derivativos preenche, na óptica de Chow e Harrisson (2002), duas premissas essenciais para realização de uma pesquisa acadêmica: (i) é um problema "real" das organizações que pode comprometer a continuidade da entidade e (ii) é um assunto que todavia não é consenso na literatura, sendo objeto de constante debate entre órgãos reguladores e comunidade científica.

Primeiramente, nota-se que o uso "indevido" dos derivativos já causou grandes prejuízos às empresas no âmbito internacional. Dentre os casos mais conhecidos tem-se Procter and Gamble, Barings, Orange County, Savings and Loans, Banesto e Long Term Capital Management (LOPES; LIMA, 2003).

De maneira geral, se tinha no Brasil a impressão de que o uso indevido desses instrumentos era problema apenas das empresas estrangeiras. Contudo, recentes escândalos evidenciaram que esse problema atinge também o cenário nacional, sendo que os prejuízos incorridos no ano de 2008 por algumas empresas brasileiras como a Sadia e a Aracruz, em decorrência da utilização indevida dos derivativos, possuem magnitude semelhante aos maiores já registrados no mundo.

$\mathrm{Na}$ Sadia, por exemplo, conforme mencionado no Relatório da Administração

as operações com derivativos geraram uma despesa financeira de $\mathrm{R} \$ 2,5$ bilhões em 2008, sendo que já foram realizados R\$ 705,9 milhões (efeito caixa) e o restante, $\mathrm{R} \$ 1,8$ bilhão, foi reconhecido nas demonstrações 
financeiras de acordo com a Lei $n^{\circ} 11.638 / 07$, com efeito apenas contábil. (VALOR ECONÔMICO ONLINE, 2009a).

Em decorrência disso, a Sadia teve um prejuízo de R\$ 2,484 bilhões em 2008, o maior de sua história de 64 anos.

A Aracruz também foi bastante afetada por operações semelhantes. Conforme evidenciado na Nota Explicativa 15 - Gerenciamento de Riscos e Instrumentos Financeiros do seu Balanço de 2008, "o resultado de operações com derivativos em 31 de dezembro de 2008 gerou uma perda de R\$ 4,6 bilhões, resultantes principalmente das operações com Swap Taxa de Juros, Sell Target Forward e Swap Libor (Pré-Pagamento)". Em razão dessas operações, a empresa possui, no passivo não circulante, uma dívida cujo montante é de R\$ 5.287.523 mil (R\$ 8.744.231 mil, no consolidado).

Em razão dessa perda, a Delloitte Touche Tohmatsu, empresa responsável pela auditoria dos balanços da Aracruz no exercício findo em 2008, mencionou a possibilidade da descontinuidade da empresa, conforme parágrafo de ênfase abaixo:

\begin{abstract}
As demonstrações financeiras acima referidas foram elaboradas na premissa da Companhia continuar no curso normal de seus negócios. Conforme divulgado na nota explicativa 2 (a), em decorrência dos prejuízos gerados em 2008 com operações envolvendo instrumentos financeiros derivativos, houve um aumento substancial do passivo da Companhia em 31 de dezembro de 2008. Adicionalmente, conforme descrito no parágrafo 4 acima e na nota explicativa 14 (c) e (d), tratativas estão sendo mantidas com instituições financeiras credoras para renegociar as condições e prazos para pagamento da dívida. Os planos da Administração com relação a este assunto, bem como os planos para arcar com o ônus assumido em função da dívida com os instrumentos financeiros também estão descritos na nota explicativa 2 (a). A continuidade normal dos negócios da Companhia depende do sucesso na execução desses planos. As demonstrações financeiras não apresentam quaisquer ajustes que possam resultar do insucesso na execução de tais planos (ARACRUZ, 2008)
\end{abstract}

Do mesmo modo, no âmbito regulatório, pode-se dizer que a contabilização, mensuração e divulgação das operações com derivativos têm gerado diversos debates nos últimos anos. No cenário norte-americano, a competência do Financial Accounting Standards Board (FASB) para normatizar esse assunto chegou a ser questionada em razão da demora de mais de uma década para elaborar um pronunciamento especifico sobre o assunto, o SFAS -133. (LOPES; LIMA, 2001).

Recentemente, em razão da crise financeira iniciada nos Estados Unidos, a regulamentação dos derivativos está novamente sendo questionada. Para Henry Paulson, ex-secretário do Tesouro dos Estados Unidos e presidente da Goldman Sachs, a crise expôs sérias falhas em muitos aspectos do sistema financeiro, sendo que haverá propostas para uma regulamentação mais efetiva em áreas como os derivativos (FOLHA DE SÃO PAULO, 2009).

No dia 2 de abril de 2009, também em razão da crise financeira, o FASB emitiu um posicionamento (staff position), flexibilizando as regras de marcação a mercado para os instrumentos financeiros dos bancos. Aparentemente, a repercussão na mídia desse posicionamento foi bastante negativa. Os críticos argumentam que ao não se registrar os papéis pelo seu valor de mercado, em caso de necessidade de venda dos ativos, a perda acabará aparecendo de qualquer maneira, sendo que o investidor fica sem saber se o balanço publicado realmente reflete números reais (VALOR ECONOMICO ONLINE, 2009b). Ressalta-se que essa foi uma posição apenas do FASB, sendo que o IASB, pelo menos até o momento, manteve a exigência de marcação a mercado. 
Já no dia 6 de abril, o FASB emitiu o posicionamento - Interim Disclosures about Fair Value of Financial Instruments - que teve como objetivo exigir maior transparência no que diz respeito às operações com instrumentos financeiros, ressaltando a importância do disclosure. Nesse sentido, percebe-se que uma das políticas mais utilizadas pelos órgãos reguladores nos momentos de crise e turbulência nos mercados internacionais é justamente o aumento do disclosure corporativo (SHIN, 2003).

No cenário nacional, antes da publicação da Deliberação CVM nº. 566, que aprovou o pronunciamento técnico CPC 14 do Comitê de Pronunciamentos Contábeis, os derivativos não eram registrados no balanço, sendo considerados off-balance sheet itens. Nesse período, havia ainda o Plano Contábil das Instituições Financeiras (COSIF), que eram fonte de orientação para as instituições financeiras brasileiras, que no tocante aos derivativos, também era distinto das normas internacionais (LOPES; CARVALHO, 1999). Nesse sentido, percebe-se que essas operações são um ponto bastante controverso, não havendo ainda consenso entre os órgãos reguladores, principalmente em razão de um dos motivos da crise ter sido a utilização de "derivativos tóxicos" por algumas instituições financeiras norteamericanas.

Finalmente, no âmbito acadêmico, uma busca realizada nos principais congressos e periódicos da área de Contabilidade e Finanças evidenciou que o tema é, todavia, pouco abordado pela comunidade cientifica brasileira. Nesse sentido, o presente estudo estende as pesquisas anteriores, principalmente os trabalhos de Carvalho (1999), Lopes (1999), Lopes e Carvalho (1999), Lopes e Santos (2003), Costa Junior (2003), Darós e Borba (2005) e Moreira, Niyama e Santana (2006).

0 restante deste trabalho está estruturado da seguinte forma. A seção 2 apresenta considerações acerca do objetivo de regulação na contabilidade. A seção 3 discute os instrumentos financeiros derivativos e estudos anteriores. Na seção 4 são descritos os aspectos metodológicos do estudo. A seção 5 evidencia os resultados das análises e a seção 6 apresenta as considerações finais da pesquisa.

\section{OBJETIVO DA REGULAÇÃO NA CONTABILIDADE}

De acordo com Levitt (1998), ex-presidente da Security Exchange Comission (SEC), o sucesso de um mercado de capitais é diretamente dependente da qualidade das normas contábeis e de disclosure. Segundo esse mesmo autor, desde que a SEC foi criada em 1944, a postura tem sido de requerer que as empresas que querem ter seus títulos negociados no mercado norte-americano obedeçam às exigências de disclosure como uma forma de prevenir divulgações incompletas e tendenciosas (LEVITT, 1998).

Mas até que ponto uma norma ou lei deve exigir a divulgação de informações aos investidores? (BAUMS, 2002). De acordo com Lev (1988), como não se sabe com certeza que informações são efetivamente relevantes para os usuários e também devido à vasta gama de usuários que as demonstrações contábeis possuem, não está claro qual critério os órgãos reguladores deveriam utilizar para decidir o que deveria ser divulgado pelas companhias.

Pode-se dizer que, mesmo sem obrigatoriedade, empresas teriam incentivos para voluntariamente divulgar informações desde que os benefícios esperados superassem os custos (VERRECCHIA, 2001; DELLOF, 2008). A idéia subjacente, baseada no conceito do unraveling argument (MILGROM, 1981), é de que sem o disclosure de informações, investidores não conseguem distinguir entre as boas e más empresas. Assim, eles ofereceriam um valor que reflete a média entre o valor das ações das empresas boas e 
más. Logo, as empresas com valor acima da média possuem incentivos para evidenciar informações privadas acerca de seu verdadeiro valor. Isso ocorre porque existe um custo de ser avaliado como um "abacaxi" (AKERLOF, 1970). De acordo com Stiglitz (1981) se algumas empresas divulgarem informações, e outras não, o mercado assumirá que as empresas que não o fazem tiveram um retorno baixo.

Nessa óptica, espera-se que as empresas divulguem voluntariamente informações se existem benefícios com o disclosure, pois invariavelmente elas arcarão com os custos da não-divulgação. Assim, percebe-se que mesmo que não existisse obrigatoriedade, algumas empresas ainda divulgariam informações, desde que os benefícios superassem os custos pois, segundo Leuz e Wysocki (2008), nesses casos as companhias já teriam incentivos para isso.

Mas, e quando isso não ocorre? Assumindo-se uma racionalidade econômica por parte dos gestores, na ausência de obrigatoriedade, não haveria disclosure de determinada informação quando os custos de sua divulgação fossem superiores aos seus benefícios. Ora, nesse cenário, existiria um gap entre o que as empresas estão dispostas a evidenciar e o que os usuários efetivamente demandam, e essa seria justamente a razão da regulação: exigir as informações que os usuários necessitam e que as empresas não estão dispostas a divulgar voluntariamente (WEIL, 2002, grifo nosso).

Assim, uma das possíveis justificativas para a regulação é sua função como mecanismo de comprometimento, já que obriga a empresa a divulgar informação nos tempos bons ou ruins (BUSHEE; LEUZ, 2005). Consequentemente, a regulação seria justificada como uma forma de "forçar" a empresa a divulgar informações mesmo quando isso trouxesse mais malefícios do que benefícios. A idéia é que o disclosure deva ser obrigatório para as informações que as empresas não têm intenção de divulgar voluntariamente (RAFFOUNIER, 1995). Os defensores da regulação do disclosure argumentam que as empresas não estão dispostas a aumentar o nível de divulgação de suas informações, a não ser quando obrigadas (YAMAMOTO; SALOTTI, 2006).

De acordo com Beaver (1998), o mercado não regulado geraria investidores com informações desiguais. Dentro desse cenário, a regulação assume um papel de justiça, já que seria injusto não proteger os menos informados dos mais informados. Logo, uma das visões acerca da regulação atesta que sua função é justamente proteger e beneficiar o mercado ou maior parte dele (STIGLER, 1971).

Para Lev (1988) um mecanismo descentralizado e não regulado de divulgação, que objetive aumentar a equidade do mercado não é disponível nos dias atuais. De acordo com esse mesmo autor, a equidade pode ser definida como uma igualdade de oportunidade, que implica a igualdade de acesso a informações relevantes para os usuários, que pode ser caracterizada por um estado de distribuição simétrico entre os usuários. Assim, a necessidade de regulação do disclosure deriva da existência de assimetria informacional, sendo que cabe ao órgão regulador exigir que a empresa forneça informação que de alguma maneira reduza essa assimetria (WEIL, 2002).

Assim, nota-se que um dos objetivos da regulação é a redução da assimetria informacional (BEAVER, 1998). Percebe-se, assim, a necessidade de proteger os investidores menores (menos informados), sendo que o remédio mais efetivo contra a existência de assimetria informacional é justamente remover a vantagem que os investidores mais bem informados possuem, por meio da exigência de divulgação de informações pelas empresas, que aumenta o bem estar do mercado como um todo (LEV, 1988).

Nesse sentido, percebe-se que o disclosure tem inúmeras consequências econômicas como, por exemplo, efeitos na distribuição de riqueza entre os investidores, na alocação 
do risco entre investidores e na alocação de recursos entre as empresas (BEAVER, 1998), e consequentemente, na economia (AKERLOF, 1970).

Finalmente, outro argumento importante em favor da regulação do disclosure corporativo é a vantagem da padronização da informação. De acordo com Baums (2002), como o investidor geralmente compara certo número de empresas antes de realizar um investimento, a padronização das informações relevantes da empresa economiza tempo e dinheiro ao investidor.

\section{INSTRUMENTOS FINANCEIROS DERIVATIVOS}

Os instrumentos financeiros podem ser divididos em primários, que resultam da transação original da companhia, que pode ser compra, venda, emissão, lançamento ou contratação, e secundários, que são resultantes de instrumentos financeiros primários (CARVALHO, 1996). Como os instrumentos financeiros secundários derivam dos primários, são geralmente chamados de derivativos. De acordo com ludícibus, Martins e Gelbcke (2007), pode-se conceituar os derivativos como instrumentos financeiros que dependem do valor de outro ativo.

Uma definição mais completa para os derivativos pode ser encontrada no Statement of Financial Accounting Standards $n^{\circ}$. 133 - Accounting for Derivative Instrument and Hedging Activities. De acordo com esse pronunciamento, derivativo é um instrumento financeiro, ou outro contrato, que possua as três seguintes características: (i) um ou mais ativos subjacentes e um ou mais valor nocional ou provisão de pagamento ou ambos; (ii) investimento inicial nulo ou muito menor que o necessário em outros tipos de contratos que possam produzir efeito similar; (iii) os termos do contrato permitem ou exigem a liquidação financeira, que pode se dar por mecanismos fora do contrato.

De uma maneira geral, os derivativos podem ser classificados da seguinte maneira: (i) primeira geração - contratos a termo (forward), contratos a futuro, opções e swaps; e (ii) segunda geração - straddle, strangle, strap, butterfly, box, etc. (LOPES; LIMA, 2003).

Segundo Galdi e Lopes (2007), o crescimento da utilização dos derivativos pelas empresas está diretamente associado a alterações na economia mundial como, por exemplo, o fim do padrão do ouro, choque nos preços do petróleo, maior mobilidade de capital etc. Nesse ambiente, caracterizado por uma maior volatilidade das variáveis econômicas, a gestão de risco passou a ser um ponto fundamental para as companhias (LOPES; CARVALHO, 1999).

A gestão do risco através desses instrumentos advém da ideia de que os derivativos permitem que os usuários identifiquem, isolem e gerenciem separadamente os riscos fundamentais de preços inerentes, já que uma parte exposta a um risco indesejado pode passá-lo a outra mais habilitada a correr esse risco. De acordo com Amaral (2003), esses instrumentos permitem transferir os riscos tanto do mercado como de crédito para uma terceira parte.

Contudo, apesar do objetivo principal dos derivativos ser a proteção contra oscilações de preços, taxas de juros, câmbio etc., sua utilização indevida pode causar enormes prejuízos às empresas em razão de suas características operacionais bastante peculiares que os diferenciam dos demais produtos financeiros: (i) velocidade das operações, (ii) grau de alavancagem e (iii) complexidade das operações (LOPES; LIMA, 2003). 
Outro exemplo de prejuízo com derivativos no cenário nacional no ano de 2008 ocorreu com a Vicunha Têxtil, sendo que seus auditores divulgaram o seguinte parágrafo de ênfase:

\begin{abstract}
Conforme divulgado na nota explicativa $n^{\circ}$. 1, em decorrência dos prejuízos gerados no segundo semestre de 2008 com operações envolvendo instrumentos financeiros derivativos, a situação de liquidez de curto prazo da Companhia foi afetada. A Companhia tem monitorado e gerenciado junto às instituições financeiras, a obtenção e renovação dos empréstimos e financiamentos que fazem parte do capital de giro para melhorar essa situação de liquidez de curto prazo. As demonstrações financeiras não incluem nenhum ajuste relativo à recuperação e classificação dos ativos ou aos valores e classificação dos passivos que poderiam ser necessários em função do resultado dessas medidas.
\end{abstract}

Dentro desse cenário, percebe-se que, devido à importância que essas operações podem ter na saúde financeira da companhia, um disclosure ineficiente poderia levar aos usuários informações não verdadeiras a respeito da posição de risco assumida pela companhia (AMARAL, 2003). Do mesmo modo, como os prejuízos com esses instrumentos são notícias "ruins" ao mercado, os gestores muitas vezes não possuem incentivos para divulgar voluntariamente essas informações ao mercado. A ideia subjacente é de que "se a informação é ruim e não existe uma norma que me obrigue a divulgá-la ao mercado, porque eu a divulgaria?"

Assim, percebe-se que a regulação das operações com derivativos, de modo a prover normas para o reconhecimento, mensuração dessas operações e também exigir um disclosure adequado é fundamental para que contabilidade consiga atingir seu objetivo principal - prover informações úteis a seus usuários.

\title{
3.1 NORMATIZAÇÃO ACERCA DAS OPERAÇÕES COM INSTRUMENTOS FINANCEIROS DERIVATIVOS
}

A Instrução CVM nº 235 de 23 de março de 1995 foi a primeira norma contábil emitida pela Comissão de Valores Mobiliários que dispunha sobre a divulgação, em nota explicativa, das operações com derivativos. Contudo, é mister ressaltar que não se tratava de uma norma específica sobre derivativos, e sim sobre instrumentos financeiros de uma forma geral. De fato, o foco central dessa instrução era a divulgação do valor de mercado dos instrumentos financeiros. Nesse sentido, a CVM nº 235 não estabelecia regras específicas acerca do reconhecimento, mensuração e disclosure dos instrumentos financeiros derivativos.

Mais de treze anos depois, as normas contábeis para operações com derivativos foram finalmente definidas, tornando-se obrigatórias para as companhias abertas brasileiras através da publicação da Deliberação CVM nº 566 de 17 de dezembro de 2008, que aprovou o pronunciamento técnico CPC 14 do Comitê de Pronunciamentos Contábeis.

Nota-se que o CPC 14 - Instrumentos Financeiros: Reconhecimento, Mensuração e Evidenciação visou também esclarecer o tratamento contábil preconizado pela Lei $\mathrm{n}^{\circ}$. 11.638-07 e pela Medida Provisória $n^{\circ}$. 449-08 para instrumentos financeiros, considerando seu objetivo de convergência as normas internacionais. Nesse sentido, esse pronunciamento técnico baseou-se na IAS 39 - Financial Instruments Recognition and Measurement e na IAS 32 - Financial Instruments: Disclosure and Presentation.

Dentre os principais pontos abordados pelo CPC 14 no que tange aos instrumentos financeiros derivativos, merece destaque o tópico acerca das operações de hedge (hedge accounting) e também as exigências de disclosure em nota explicativa. Contudo, conforme mencionado no referido pronunciamento, o Comitê de Pronunciamentos Contábeis entende 
que o processo de migração para as normas internacionais de contabilidade deverá ser realizado em duas etapas. Nesse sentido, o CPC 14 não aborda alguns itens presentes na IAS 39 e IAS 32 como, por exemplo, o desreconhecimento de ativos e passivos financeiros, derivativos embutidos, etc.

Do mesmo modo, visando dar complementaridade a Deliberação CVM n. 566, a Comissão de Valores Mobiliários aprovou também em 17 de dezembro de 2008, a Instrução CVM nº. 475, que dispõe sobre o disclosure de instrumentos financeiros em nota explicativa específica. Ressalta-se que a Instrução CVM $n^{\circ}$. 475/08 revogou a Instrução CVM $\mathrm{n}^{\circ}$. 235/05.

Dentre as principais inovações trazidas pela Instrução CVM n ${ }^{\circ}$ 475/08 encontra-se o quadro demonstrativo de análise de sensibilidade com os possíveis riscos e cenários adversos que podem gerar prejuízos para a companhia. De acordo com a Nota Explicativa a essa Instrução, "o quadro demonstrativo de análise de sensibilidade visa permitir que os usuários das demonstrações financeiras avaliem adequadamente o perfil de risco inerente as operações com instrumentos financeiros, principalmente os derivativos". Ressalta-se que esse quadro também está em linha com a convergência das normas contábeis brasileiras para normas internacionais de contabilidade, emitidas pelo International Accounting Standards Board (IASB), na medida em que essa informação também é requerida pela IFR7 - Financial Instruments - Disclosure.

Assim, sumarizando os aspectos mencionados nos parágrafos acima, as companhias abertas no Brasil, a partir do exercício findo em 2008, devem adequar seus balanços a Deliberação CVM n. 566/08, que aprovou o CPC 14, e a Instrução CVM n. 475/08. Ressalta-se que essas novas regras contábeis caminham no sentido da convergência para as normas internacionais de contabilidade, processo esse iniciado com a aprovação da Lei $n^{\circ}$. $11.638 / 07$.

Já no âmbito acadêmico, nota-se a existência de alguns estudos que buscaram discutir aspectos relacionados à regulação das operações com instrumentos derivativos, como por exemplo, os trabalhos de Carvalho (1999), Lopes (1999), Lopes e Carvalho (1999), e Lopes e Santos (2003). Do mesmo modo, outros estudos como, por exemplo, os trabalhos de Costa Junior (2003), Darós e Borba (2005) e Moreira, Niyama e Santana (2006) analisaram o disclosure das empresas no tocante aos instrumentos financeiros, em especial os derivativos.

No âmbito internacional, pode-se dizer que a pesquisa científica sobre o tema encontra-se em estágio mais consolidado. Nesse ambiente, merecem menção os trabalhos de Barth, Beaver e Landsman (1996), Skinner (1996), Seow e Tam (2002), entre outros que abordaram aspectos relacionados à regulação dos derivativos na ótica do FASB, disclosure e valor preditivo dessas informações para o mercado de capitais.

\section{ASPECTOS METODOLÓGICOS}

O presente trabalho pode ser classificado como uma pesquisa teórico-empírica de caráter exploratório. Para consecução do objetivo do estudo - analisar o impacto da Deliberação CVM nº. 566/08 e da Instrução CVM n . 475/08 no disclosure de informações acerca de operações com instrumentos financeiros derivativos das companhias abertas no Brasil - foram analisadas as demonstrações contábeis das empresas no exercício findo em 2007, antes da aprovação das referidas deliberações, e também no exercício findo em 2008, após a aprovação das mesmas. A ideia subjacente foi justamente comparar o nível de divulgação de informações acerca de operações com instrumentos financeiros 
derivativos ex ante e ex post de modo a verificar o impacto das novas normas contábeis tiveram no disclosure das empresas.

As demonstrações contábeis foram coletadas através do website da Bolsa de Valores de São Paulo (BOVESPA). A amostra, não-probabilística, totalizou as 100 maiores empresas abertas. De acordo com Goulart, Lima e Gregório (2007), uma companhia é considerada aberta quando promove a colocação pública de valores mobiliários (ações, debêntures, bônus de subscrição, notas comerciais, etc.) em bolsas de valores ou no mercado de balcão.

O critério para definição das maiores empresas foi o da receita bruta do exercício findo em 2007. Foram excluídas as empresas do setor financeiro por possuírem características (total das vendas, endividamento) que não podem ser comparáveis às das empresas não-financeiras. De acordo com Cooke (1989), considera-se apropriado excluir da amostra bancos, empresas de seguro e empresas financeiras em geral devido às particularidades de suas operações.

Para analisar o disclosure das empresas utilizou-se a técnica da análise de conteúdo. De acordo com Beretta e Bozzolan (2007), esse é o método mais utilizado nos estudos sobre disclosure, pois fornece credibilidade e inferência para análise de acordo com determinado contexto. Essa técnica tem como objetivo estudar de maneira rigorosa e sistemática a natureza das mensagens (KRIPPENDORFF, 1990).

Para a utilização da análise de conteúdo, faz-se necessária a definição de categorias e subcategorias para que o texto possa ser classificado, agrupado, por meio de características em comum das informações analisadas. Isto é, classificam-se as informações similares em categorias a fim de se realizar melhores inferências (BARDIN, 1977).

Assim, buscou-se elaborar uma métrica para análise do disclosure de informações acerca de instrumentos derivativos. Como o objetivo do trabalho é verificar o impacto da Deliberação CVM $n^{\circ}$. 566/08 e da Instrução CVM nº 475/08, a métrica foi elaborada justamente com base nas informações nelas exigidas. Do mesmo modo, buscou-se agrupar as informações em categorias e subcategorias de modo a facilitar a coleta e análise dos dados.

Com base nesse critério elaborou-se uma métrica para análise do disclosure de informações acerca de instrumentos financeiros derivativos, composta por quatro categorias e 22 subcategorias: informações qualitativas (5), informações quantitativas (6), valores dos derivativos (5) e analise de sensibilidade (6). O Quadro 1 apresenta a métrica juntamente com a respectiva menção da lei que exige a divulgação da informação. 


\section{Informações Qualitativas}

Política de utilização dos derivativos

Objetivos e estratégia de gerenciamento de riscos

Riscos associados a cada estratégia de atuação no mercado

Critérios de avaliação e mensuração do valor justo

Principais transações e compromissos futuros

\section{Informações Quantitativas}

Valores registrados em conta de Ativo e Passivo

Valores agrupados por Tipo

Ganhos e Perdas no Período hedge e não-hedge

Valor e tipo de margem dada em garantia

Efeitos da adoção inicial da

Deliberação CVM n'. 566

3. Valores dos Derivativos

Valor de Referencia Nocional (Período Atual)

Valor de Referencia Nocional

(Período Anterior)

Valor Justo (Período Atual)

Valor Justo (Período Anterior)

Valores a Receber (Recebido) e/ou

Valores a Pagar (Pago) no Período

4. Analise de Sensibilidade

Identificação dos Principais Riscos

Métodos e Premissas Utilizadas

Definição e Impacto do cenário provável

Definição e Impacto do cenário pessimista I

Definição e Impacto do cenário

pessimista II

Exposição líquida do hedge

accounting

\section{Parágrafo 59 da Deliberação CVM nº 566 de 2008}

É obrigatória a divulgação, em notas explicativas às demonstrações contábeis, de informações qualitativas e quantitativas relativas aos instrumentos financeiros derivativos, destacados, no mínimo, os seguintes aspectos: (a) política de utilização;

(b) objetivos e estratégias de gerenciamento de riscos, particularmente a política de proteção patrimonial (hedge);

(c) riscos associados a cada estratégia de atuação no mercado, adequação dos controles internos e parâmetros utilizados para o gerenciamento desses riscos e os resultados obtidos em relação aos objetivos propostos;

(d) o valor justo de todos os derivativos contratados, os critérios de avaliação e mensuração, métodos e premissas significativas aplicadas na apuração do valor justo;

(i) principais transações e compromissos futuros objeto de proteção patrimonial (hedge) de fluxo de caixa, destacados os prazos para o impacto financeiro previsto;

\section{Parágrafo 59 da Deliberação CVM nº 566 de 2008}

(e) valores registrados em contas de ativo e passivo segregados, por categoria, risco e estratégia de atuação no mercado, aqueles com o objetivo de proteção patrimonial (hedge) e aqueles com o propósito de negociação;

(f) valores agrupados por ativo, indexador de referência, contraparte, local de negociação (bolsa ou balcão) ou de registro e faixas de vencimento, destacados os valores de referência, de custo, justo e risco da carteira ;

(g) ganhos e perdas no período, agrupados pelas principais categorias de riscos assumidos, segregados aqueles registrados no resultado e no patrimônio líquido;

(h) valores e efeito no resultado do período de operações que deixaram de ser qualificadas para a contabilidade de operações de proteção patrimonial (hedge), bem como aqueles montantes transferidos do patrimônio líquido em decorrência do reconhecimento contábil das perdas e dos ganhos no item objeto de hedge;

(j) valor e tipo de margens dadas em garantia;

(1) efeitos da adoção inicial deste Pronunciamento.

\section{Artigo $1^{\circ}$ da Instrução CVM 475 de 2008}

As companhias abertas devem divulgar, em nota explicativa específica, informações qualitativas e quantitativas sobre todos os seus instrumentos financeiros, reconhecidos ou não como ativo ou passivo em seu balanço patrimonial. $\S 4^{\circ}$ As informações quantitativas da nota explicativa de que trata o caput devem ser apresentadas em forma de tabela observando, no que for aplicável, o exemplo constante do Anexo I.

\section{Artigo $3^{\circ}$ da Instrução CVM 475 de 2008}

$\S 1^{\circ} \mathrm{O}$ quadro demonstrativo de análise de sensibilidade de que trata $\mathrm{o}$ caput deve ser divulgado e elaborado da seguinte forma:

I - identificar os tipos de risco que podem gerar prejuízos materiais para a companhia, incluídas as operações com instrumentos financeiros derivativos originadoras desses riscos;

II - discriminar os métodos e premissas usadas na preparação da análise de sensibilidade;

III - definir o cenário mais provável, na avaliação da administração, além de 2 (dois) cenários que, caso ocorram, possam gerar resultados adversos para a companhia;

Quadro 1 - Métrica para Análise do Disclosure de Informações Acerca dos Derivativos

Fonte: Elaborado pelos Autores com base na CVM 566/08 e CVM475/08 


\subsection{LIMITAÇÕES DA PESQUISA}

Primeiramente, com relação ao procedimento de coleta de dados, é importante salientar que a análise de conteúdo opera entre dois pólos: rigor da objetividade e fertilidade da subjetividade (BARDIN, 1977). Assim, a decisão acerca da presença ou não de determinada informação acerca das operações com instrumentos financeiros derivativos no balanço das empresas envolve uma subjetividade inerente, que muitas vezes baseia-se na percepção dos pesquisadores que coletam os dados.

Com relação ao documento escolhido para análise do disclosure, embora as demonstrações contábeis sejam a principal fonte de divulgação das informações corporativas, outros canais de comunicação alternativos também contribuem para a redução da assimetria informacional. Nesse sentido, ressalta-se que a empresas poderiam utilizar outros canais de divulgação para evidenciar suas operações com instrumentos financeiros derivativos, sendo que o presente estudo analisou apenas as demonstrações contábeis.

Finalmente, é importante salientar que foram analisadas apenas as 100 maiores companhias não-financeiras listadas na Bovespa. Nesse sentido, trata-se de uma amostra não-probabilística, sendo que os resultados encontrados não devem ser generalizados para outras empresas ou para as mesmas empresas durante outros períodos de tempo.

\section{RESULTADOS}

Apesar de a amostra desse estudo compreender as 100 maiores empresas nãofinanceiras, listadas na Bolsa de Valores de São Paulo (BOVESPA), as análises serão apresentadas para um menor número de empresas em razão de: (i) não utilização de derivativos por parte de algumas empresas, (ii) não menção à existência ou não de derivativos, (iii) cancelamento de registro de companhia aberta na CVM no ano de 2008 e (iv) não divulgação dos balanços de 2008 até a data de encerramento para elaboração desse artigo, em 10 de abril de 2009. A Tabela 1 ilustra a composição da amostra final de empresas.

Tabela 1 - Composição da Amostra Final de Empresas Analisadas

\begin{tabular}{|l|c|c|}
\hline & $\mathbf{3 1 / 1 2 / 2 0 0 7}$ & $\mathbf{3 1 / 1 2 / 2 0 0 8}$ \\
\hline Amostra inicial & 100 & 100 \\
\hline Não utilizaram derivativos & $(18)$ & $(21)$ \\
\hline Não informaram se utilizaram derivativos ou não & $(10)$ & $(2)$ \\
\hline Não divulgaram Balanços até 10/04/2009 & - & $(3)$ \\
\hline Tiveram registro de companhias abertas cancelados na CVM & - & $(8)$ \\
\hline \multicolumn{1}{|c|}{ Amostra Final } & $\mathbf{( 7 2 )}$ & $\mathbf{( 6 6 )}$ \\
\hline
\end{tabular}

Fonte: Os autores

É mister ressaltar que duas empresas (Cosan e Açúcar Guarani) não divulgaram seus balanços até de 10 abril de 2009, e não o fizeram por adotarem exercícios sociais distintos em razão de suas atividades operacionais. Notou-se também que oito das 100 empresas analisadas no ano de 2007 não disponibilizaram seus balanços no website da Bovespa, pois se tornaram companhias fechadas. São elas: Arcelor, Petrolex, Suzano Petroquímica, Petroquímica União, Ipiranga Distribuidora, Ipiranga Petróleo, Ipiranga Refinaria e Vigor.

Um total de 18 empresas em 2007 e 21 empresas em 2008 não utilizou instrumentos derivativos, mas evidenciou essa informação como, por exemplo, a Ponto Frio, que 
informou que "a Companhia e suas controladas não possuem compromissos decorrentes de instrumentos derivativos em 31 de dezembro de 2007". Contudo, surpreendentemente, no ano de 2007, dez empresas não fizeram qualquer menção à utilização ou não desses instrumentos. A Suzano Petroquímica foi uma dessas empresas que não divulgou uma única informação sobre derivativos na Nota - Instrumentos Financeiros, mas evidenciou "ganhos de hegde/swap" na sua Nota - Resultados Financeiros. Obviamente esse ganho é resultado de uma operação com derivativos que a empresa não informou aos seus usuários externos.

Contudo, é possível notar uma redução drástica no ano de 2008 , com relação ao número de empresas que não divulgaram qualquer tipo de informação acerca dos derivativos. De certa forma, esse é um primeiro indício de que o disclosure das empresas melhorou.

A seguir, são apresentados os resultados das análises das informações requeridas pela Deliberação CVM n . 566/08 e da Instrução CVM nº.475/08. Ressalta-se que essas análises foram realizadas tendo como base as empresas que evidenciaram algum tipo de informação acerca de derivativos: 72 empresas em 2007 e 66 empresas em 2008.

Tabela 2 - Disclosure de Informações Qualitativas sobre Derivativos

\begin{tabular}{|l|c|c|c|c|}
\hline \multirow{2}{*}{ Categoria de Observação: Informações Qualitativas } & \multicolumn{2}{|c|}{ Ano de 2007 } & \multicolumn{2}{c|}{ Ano de 2008 } \\
\cline { 2 - 5 } & Empresas & $\mathbf{\%}$ & Empresas & \% \\
\hline Política de Utilização dos Derivativos & 70 & $97,22 \%$ & 66 & $100,00 \%$ \\
\hline Objetivos e Estratégia de Gerenciamento de Riscos & 66 & $91,67 \%$ & 66 & $100,00 \%$ \\
\hline Riscos Associados a cada Estratégia de Atuação no Mercado & 6 & $8,33 \%$ & 22 & $33,33 \%$ \\
\hline Critérios de Avaliação e mensuração do Valor Justo & 6 & $8,33 \%$ & 31 & $46,97 \%$ \\
\hline Principais transações e compromissos futuros & 5 & $6,94 \%$ & 24 & $36,36 \%$ \\
\hline
\end{tabular}

Fonte: Os autores

As recentes perdas com derivativos envolvendo empresas brasileiras (Sadia, Aracruz, Vicunha Têxtil, etc.) levantaram questões acerca do "real" objetivo da utilização desses instrumentos pelas empresas. Aparentemente, algumas empresas não estavam utilizando esses instrumentos para se proteger, mas sim especular no mercado. Nesse sentido, pode-se dizer que as informações acerca dos objetivos, estratégias e política de utilização desses instrumentos são importantes, pois evidenciam o "porquê" e o "como" realizar essas operações de modo a mitigar os riscos que a empresa enfrenta. Como ponto positivo, nota-se que a vasta maioria da empresas evidencia essa informação.

Por outro lado, apesar de haver uma melhora significativa com no ano de 2008, menos da metade das empresas analisadas evidenciou informações acerca dos critérios de avaliação a valor justo. A empresa JBS informou apenas que "os valores de mercado dos instrumentos financeiros e contratos de derivativos em 31 de dezembro de 2007 foram estimados com base em preços cotados no mercado". A Braskem, no ano de 2007, também foi bastante evasiva, informando que "para determinar o valor de mercado estimado dos derivativos são utilizadas cotações de operações semelhantes ou informações públicas disponíveis no mercado financeiro bem como metodologias de avaliação geralmente aceitas e praticadas pelas contrapartes”. Esse tipo de informação, bastante genérica, tem pouca utilidade para o usuário. 
Tabela 3 - Disclosure de Informações Quantitativas sobre Derivativos

\begin{tabular}{|l|c|c|c|c|}
\hline \multirow{2}{*}{$\begin{array}{c}\text { Categoria de Observação: Informações } \\
\text { Quantitativas: }\end{array}$} & \multicolumn{2}{c|}{ Ano de 2007 } & \multicolumn{2}{c|}{ Ano de 2008 } \\
\cline { 2 - 5 } & Empresas & \% & Empresas & \% \\
\hline Valores registrados em conta de Ativo e Passivo & 21 & $29,17 \%$ & 42 & $63,64 \%$ \\
\hline Valores agrupados por Tipo & 24 & $33,33 \%$ & 55 & $83,33 \%$ \\
\hline Ganhos e Perdas no Período & 41 & $56,94 \%$ & 46 & $69,70 \%$ \\
\hline Efeito no resultado das operações de hedge e não-hedge & 32 & $44,44 \%$ & 32 & $48,48 \%$ \\
\hline Valor e tipo de margem dada em garantia & 0 & $0,00 \%$ & 33 & $50,00 \%$ \\
\hline Efeitos da adoção inicial da Deliberação CVM no. 566 & 0 & $0,00 \%$ & 30 & $45,45 \%$ \\
\hline
\end{tabular}

Fonte: Os autores

Novamente percebe-se que houve uma melhora significativa no disclosure das empresas no ano de 2008. Contudo, nota-se que nem todas as empresas analisadas seguem o que é requerido pelas normas. Menos de $50 \%$ divulgaram aos usuários os efeitos da adoção inicial da CVM nº. 566. Sobre esse último quesito, a Aracruz informou que

já registrava seus instrumentos financeiros ao valor justo e seguia as classificações contábeis que foram requeridas pela norma. Portanto, a adoção não teve efeito nas suas posições financeiras em 31 de dezembro de 2008 e de 2007 ou em seus resultados dos exercícios findos naquelas datas.

Outro aspecto evidenciado por menos da metade das empresas é o efeito no resultado das operações de hedge e não hedge. Do mesmo modo, apesar de aproximadamente $70 \%$ das empresas evidenciarem os ganhos e perdas com derivativos, algumas dela o fazem na Nota Explicativa - Resultado Financeiro, e não na Nota Instrumentos Financeiros e Gerenciamento de Risco. De certa forma, a divulgação de todas as informações que envolvem derivativos em uma mesma nota tornar-se-iam mais amigáveis (user friendly) para o usuário.

Tabela 4 - Disclosure de Valores dos Derivativos

\begin{tabular}{|l|c|c|c|c|}
\hline \multirow{2}{*}{ Categoria de Observação: Valores dos Derivativos } & \multicolumn{2}{|c|}{ Ano de 2007 } & \multicolumn{2}{c|}{ Ano de 2008 } \\
\cline { 2 - 5 } & Empresas & \% & Empresas & \% \\
\hline Valor de Referencia Nocional (Período Atual) & 47 & $65,28 \%$ & 63 & $95,45 \%$ \\
\hline Valor de Referencia Nocional (Período Anterior) & 25 & $34,72 \%$ & 42 & $63,64 \%$ \\
\hline Valor Justo (Período Atual) & 25 & $34,72 \%$ & 60 & $90,91 \%$ \\
\hline Valor Justo (Período Anterior) & 18 & $25,00 \%$ & 47 & $71,21 \%$ \\
\hline Valores a Receber e/ou Valores a Pagar no Período & 17 & $23,61 \%$ & 55 & $83,33 \%$ \\
\hline
\end{tabular}

Fonte: Os autores

Percebe-se que a grande maioria das empresas atendeu a legislação no ano de 2008 no que diz respeito aos valores de referência, valor justo e valores a receber e/ou pagar. Contudo, nota-se que algumas empresas evidenciaram apenas a informação no período atual e isso prejudica a análise desses valores, pois não há como compará-los aos períodos anteriores. 
Tabela 5 - Disclosure do Demonstrativo de Análise de Sensibilidade dos Derivativos

\begin{tabular}{|l|c|c|c|c|}
\hline \multirow{2}{*}{ Categoria de Observação: Analise de Sensibilidade } & \multicolumn{2}{|c|}{ Ano de 2007 } & \multicolumn{2}{c|}{ Ano de 2008 } \\
\cline { 2 - 5 } & Empresas & $\mathbf{\%}$ & Empresas & \% \\
\hline Identificação dos Principais Riscos & 0 & $0,00 \%$ & 59 & $89,39 \%$ \\
\hline Métodos e Premissas Utilizadas & 0 & $0,00 \%$ & 58 & $87,88 \%$ \\
\hline Definição e Impacto do cenário provável & 0 & $0,00 \%$ & 59 & $89,39 \%$ \\
\hline Definição e Impacto do cenário pessimista I & 0 & $0,00 \%$ & 59 & $89,39 \%$ \\
\hline Definição e Impacto do cenário pessimista II & 0 & $0,00 \%$ & 59 & $89,39 \%$ \\
\hline Exposição líquida do hedge accounting & 0 & $0,00 \%$ & 28 & $42,42 \%$ \\
\hline
\end{tabular}

Fonte: Os autores

Conforme evidenciado na tabela acima, nenhuma empresa destacou o demonstrativo de análise de sensibilidade no ano de 2007. Em contrapartida, a grande maioria delas o fez em 2008. Nesse sentido, nota-se o alto impacto que a norma teve na medida em que exigiu informações que as empresas não divulgavam voluntariamente.

Em 2008, uma das poucas empresas que não divulgaram esse quadro foi a Natura, a qual informou que "para os instrumentos derivativos financeiros demonstrados no item e-1, a Administração da Sociedade entende que não se aplica a análise de sensibilidade, pois há passivos equivalentes registrados no balanço patrimonial, tornando as operações atreladas". Ressalta-se que a norma não menciona nenhuma isenção de evidenciação nesses casos. Pelo contrário, a Nota Explicativa a Instrução CVM n ${ }^{\circ}$. 475/08 ressalta a importância do quadro de sensibilidade, mencionado que

devido à complexidade inerente das operações com derivativos, a evidenciação do valor justo das operações não é suficiente para que os usuários externos consigam avaliar adequadamente o perfil de risco das instituições. As perdas podem ser muito maiores e mais alavancadas que o valor justo das operações pode sugerir.

Ainda sobre a importância dessa informação, Eliseu Martins, diretor da CVM, menciona "Eu acho que é impossível alguém [fora da companhia] construir sozinho esse quadro" (VALOR ECONOMICO ONLINE, 2008). Já Reginaldo Alexandre, vice-presidente da Associação dos Profissionais de Investimentos do Mercado de Capitais de São Paulo, menciona que "talvez, se Sadia e Aracruz relatassem seus instrumentos dessa forma, o mercado já tivesse atribuído um desconto de risco às ações. E mais: há quem diga que, com tal transparência, talvez esses contratos não teriam sequer sido feitos" (VALOR ECONOMICO ONLINE, 2008).

\section{CONSIDERAÇÕES FINAIS}

O objetivo do presente trabalho foi analisar o impacto da Deliberação CVM $\mathrm{n}^{\circ}$. 566/08 e da Instrução $n^{\circ}$. CVM475/08 no disclosure de informações de operações com instrumentos financeiros derivativos das companhias abertas no Brasil. A motivação para condução do estudo resultou da premissa de que a prática nem sempre é determinada pela normatização (BALL; KOTHARI; ROBIN, 2000). Justifica-se a condução da pesquisa em razão dos recentes prejuízos enfrentados por empresas brasileiras em razão das operações com derivativos, sendo que a revisão da literatura existente demonstrou que o tema é pouco abordado pela comunidade científica brasileira na área de Contabilidade e Finanças.

Os balanços das maiores empresas não-financeiras listadas na BOVESPA foram analisados através da técnica de análise de conteúdo, utilizando como base uma métrica construída a partir das novas normas e composta por quatro categorias e 22 subcategorias: 
informações qualitativas (5), informações quantitativas (6), valores dos derivativos (5) e análise de sensibilidade (6).

Dentre os principais resultados da pesquisa destacam-se:

$>$ No exercício de 2007, um total de 10 empresas não fez qualquer menção acerca da utilização de derivativos em nota explicativa, o que, de certa forma, pode gerar dúvidas aos usuários das demonstrações contábeis acerca da utilização ou não desses instrumentos. Em 2008, apenas duas empresas exibiram esse mesmo comportamento.

$>$ A maioria da empresas divulgou o valor justo dos seus derivativos no ano de 2008, mas apenas 8,33\% em 2007 e 33,33\% em 2008 divulgaram os critérios de avaliação e mensuração utilizados.

$>$ Menos de 50\% divulgaram aos usuários os efeitos da adoção inicial da CVM nº 566.

$>0$ quadro de análise de sensibilidade não foi evidenciado por nenhuma empresa em 2007. Em contrapartida $90 \%$ das empresas analisadas evidenciaram esse demonstrativo em 2008. Nota-se o alto impacto que a norma teve na medida em que exigiu informações que a empresas não divulgavam voluntariamente.

De maneira geral, nota-se que as normas tiveram impacto positivo no disclosure da empresas, na medida em que em todos os 22 itens analisados houve aumento de divulgação.

Aparentemente, a norma atingiu seu objetivo, que era justamente exigir que as empresas passassem a divulgar aquilo que não estavam divulgando voluntariamente. Esses resultados podem ser interpretados de acordo com a Teoria do Disclosure Voluntário (VERRECCHIA, 2001), na qual o disclosure só ocorre se os benefícios gerados pela divulgação das informações voluntárias (redução do custo de capital, aumento da liquidez das ações, etc.) forem superiores aos seus custos (custo de elaboração e publicação das demonstrações, custos de propriedade). 0 caso do quadro de sensibilidade parece ilustrar bem essa premissa, já que como se tratava de uma informação aparentemente negativa, os custos para a empresa aparentavam ser superiores aos benefícios, e isso, de certa forma, parece-nos, inibia a divulgação dessa informação. Nesse sentido, as normas possuem o papel fundamental de "forçar" tal divulgação.

Contudo, ressalta-se que as empresas analisadas, em 2008, ainda não divulgaram integralmente o exigido pelas normas. Nesse aspecto, destaca-se o papel fundamental atribuído à CVM, pois cabe a ela o poder de exigir republicações de balanços nos casos de omissão ou insuficiência de informação. Afinal, “lei sem punição é conselho".

Contudo, ressalta-se que as empresas analisadas, em 2008, ainda não divulgaram integralmente o exigido pelas normas. As análises evidenciaram que o disclosure de muitas empresas não atende as exigências legais. Nesse aspecto, destaca-se o papel fundamental atribuído à CVM, pois cabe a ela o poder de enforcement das normas contábeis, de modo a exigir republicações de balanços nos casos de omissão ou insuficiência de informação. Afinal "lei sem punição é conselho".

Finalmente, futuros trabalhos poderiam buscar explicações para a não conformidade plena as normas, que são obrigatórias. Do mesmo modo, novas pesquisas poderiam relacionar o nível de adequação às normas com variáveis da empresa como, por exemplo, tamanho, setor, rentabilidade, presença no mercado norte-americano, etc. 


\section{REFERÊNCIAS}

AKERLOF, George. The market for "lemons": Quality uncertainty and the market mechanism. Quarterly Journal of Economics, v. 84, p. 488-500, 1970.

AMARAL, Carlos. Derivativos: 0 que são e a evolução quanto ao aspecto contábil. Revista Contabilidade e Finanças, São Paulo, n. 32, p. 71-80, 2003.

BALL, Ray; KOTHARI, S. P.; ROBIN, Ashok. The effect of international institutional factors on properties of accounting earnings. Journal of Accounting and Economics, v. 29, p. 151, 2000.

BARDIN, Laurence. Análise de conteúdo. Lisboa: Edições 70, 1977.

BARTH, Mary; BEAVER, William; LANDSMAN, Wayne. Value-relevance of banks' fair value disclosures under SFAS n. 107. The Accounting Review, v.71, 513-537, 1996.

BAUMS, Theodor. Changing patterns of corporate disclosure in continental Europe: The example of Germany. European Corporate Governance Institute (EGCI) - Law Working Paper. Social Science Research Network. Disponível em: <www.ssrn.com>. Outubro, 2002. Acesso em: 11 set. de 2008.

BEAVER, William. Financial reporting: An accounting revolution. New Jersey: Prentice Hall, 1998.

BERETTA, Sérgio; BOZZOLAN, Saverio. Quality versus quantity: The case of forward-looking disclosure. Journal of Accounting, Auditing and Finance, Forthcoming, 2008. Social Science Research Network. Disponível em: <www.ssrn.com>. Janeiro, 2007. Acesso em: 11 set. 2008.

BRASIL, Lei 11.638 de 28 de dezembro de 2007. Altera e revoga dispositivos da Lei no 6.404, de 15 de dezembro de 1976, e da Lei no 6.385, de 7 de dezembro de 1976, e estende às sociedades de grande porte disposições relativas à elaboração e divulgação de demonstrações financeiras. Disponível em: <http://www.planalto.gov.br/ccivil>. Acesso em: 10 jul. 2008.

BUSHEE, Brian; LEUZ, Christian. Economic consequences of SEC disclosure regulation: Evidence from OTC bulletin board. Journal of Accounting and Economics, v. 39, p. 233264, 2005.

CARVALHO, Nelson. Uma contribuição a auditoria do risco de derivativos. 1996. 117f. Tese (Doutorado em Controladoria e Contabilidade) - Faculdade de Economia, Administração e Contabilidade, Universidade de São Paulo, São Paulo, 1996.

CARVALHO, Nelson. Evidenciação de derivativos. Caderno de Estudos, São Paulo, n. 20, p. 1-16, 1999.

CHOW, Chee; HARRISON, Paul. Identifying meaningful and significant topics for research and publication: a sharing of experiences and insights by 'influential' accounting authors. Journal of Accounting and Education. v. 20, p. 183-203, 2002.

COMISSÃO DE VALORES MOBILIÁRIOS. Instrução CVM №. 235, de 23 de março de 1995. Disponível em <http: //www.cvm.gov.br>. Acesso em: 15 jan. 2009.

COMISSÃO DE VALORES MOBILIÁRIOS. Instrução CVM Nº 475, de 17 de dezembro de 2008. Disponível em <http://www.cvm.gov.br>. Acesso em: 16 jan. 2009.

COMISSÃO DE VALORES MOBILIÁRIOS. Nota Explicativa a Instrução CVM No . 475, de 17 de dezembro de 2008. Disponível em <http://www.cvm.gov.br>. Acesso em: 16 jan. 2009. 
COMISSÃO DE VALORES MOBILIÁRIOS. Deliberação CVM No .566 , de 17 de dezembro de 2008. Disponível em <http: / /www.cvm.gov.br>. Acesso em: 16 jan. 2009.

COOKE, Terence. Disclosure in the corporate annual reports of Swedish companies. Accounting and Business Research, v. 19, p. 113-124, 1989.

COSTA JUNIOR, Jorge. Uma avaliação do nível de evidenciação das companhias abertas, no Brasil, no tocante aos instrumentos financeiros. Revista Contabilidade e Finanças, São Paulo, n. 32, p. 23-39, 2003.

DARÓS, Leandro; BORBA, José Alonso. Evidenciação de instrumentos financeiros derivativos nas demonstrações contábeis: Uma análise das empresas brasileiras. Revista Contabilidade e Finanças, São Paulo, n. 39, p. 68-80, 2005.

DELOOF, Mark. Determinants of corporate financial disclosure in an unregulated environment: Evidence from the early 20th century. In: European Accounting Association Annual Congress, 31, 2008, Rotterdam.

FINANCIAL ACCOUNTING STANDARDS BOARD. SFAS 133 - Accounting for Derivative and Hedging Activities, 1998. Disponível em <http://www.fasb.org>. Acesso em: 20 jan. 2009.

GALDI, Fernando; LOPES, Alexsandro. Derivativos. In: LIMA, Iran; LIMA, Gerlando; PIMENTEL, René. Curso de mercado financeiro: Tópicos especiais. São Paulo: Atlas, 2007.

GOULART, André; LIMA, Gerlando, GREGÓRIO, Jaime. Mercado de renda variável. In: LIMA, Iran; LIMA, Gerlando; PIMENTEL, René. Curso de mercado financeiro: Tópicos especiais. São Paulo: Atlas, 2007.

INTERNATIONAL ACCOUNTING STANDARDS BOARD. IAS 32 - Financial Instruments: Disclosure and Presentation. Disponível em <http://www.iasb.org>. Acesso em: 20 jan. 2009.

INTERNATIONAL ACCOUNTING STANDARDS BOARD. IAS 39 - Financial Instruments Recognition and Measurement. Disponível em <http://www.iasb.org>. Acesso em: 20 jan. 2009.

INTERNATIONAL ACCOUNTING STANDARDS BOARD. IFRS 7 - Financial Instruments: Disclosure. Disponível em <http://www.iasb.org>. Acesso em: 20 jan. 2009.

IUDÍCIBUS, Sérgio; MARTINS, Eliseu, GELBCKE, Ernesto. Manual de contabilidade das sociedades por ações (aplicável às demais sociedades). 7.ed. São Paulo: Atlas, 2007.

KRIPPENDORFF, Klaus. Metodología de análisis de contenido: Teoría y práctica. Barcelona: Paidós Comunicación, 1990.

LEV, Baruch. Toward a theory of equitable accounting policy. The Accounting Review, v. 63, p. 1-22, 1988.

LEVITT, Arthur. The importance of high quality accounting standards. Accounting Horizons, v. 12, p. 79-82, 1998.

LEUZ, Christian; WYSOCKI, Peter. Economic consequences of financial reporting and disclosure regulation: A review and suggestions for future research. Social Science Research Network. Disponível em: <www.ssrn.com>. Março, 2008. Acesso em: 22 ago. de 2008.

LOPES, Alexsandro. Uma análise crítica do arcabouço teórico do SFAS 133: Accounting for derivative and hedging activities. Caderno de Estudos, São Paulo, n. 22, p. 1-15, 1999.

LOPES, Alexsandro; Carvalho, Nelson. Contabilização de operações com derivativos: Uma comparação entre o SFAS N ${ }^{\circ} 133$ e o arcabouço emanado pelo COSIF. Caderno de Estudos, São Paulo, n. 20, p. 1-23, 1999. 
LOPES, Alexsandro; LIMA, Iran. Perspectivas para a pesquisa em contabilidade: 0 impacto dos derivativos. Revista Contabilidade e Finanças, São Paulo, n. 26, p. 25-41, 2001.

LOPES, Alexsandro; LIMA, Iran. Contabilidade e controle de operações com derivativos. São Paulo: Thomson, 2003.

LOPES, Alexsandro; SANTOS, Nelson. A administração do lucro contábil e os critérios para determinação da eficácia do hedge accounting: Utilização da correlação simples dentro do arcabouço do SFAS No 133. Revista Contabilidade e Finanças, São Paulo, n. 31, p. 16-25, 2003.

MILGROM, Paul. Good news and bad news: Representation theorem and applications. Bell Journal of Economics, v. 12, p. 380-391, 1981.

MOREIRA, Carolina; NIYAMA, Jorge; SANTANA, Cláudio. Avaliação do nível de evidenciação contábil de operações com derivativos: Uma comparação entre as informações enviadas à CVM e à SEC pelas companhias abertas brasileiras emissoras de ADR. In: Congresso USP de Controladoria e Contabilidade, 6, 2006, São Paulo. Anais do $6^{\circ}$ Congresso USP de Controladoria e Contabilidade. São Paulo: 2006.

PAULSON, Henry. É preciso reformar a regulamentação. Folha de São Paulo. p. XX, 22 mar. 2009.

RAFFOURNIER, Bernard. The determinants of voluntarily disclosure by Swiss listed companies. European Accounting Review, v. 4, p. 261-280, 1995.

SEOW,Gym; TAM, Kinsun. The usefulness of derivative-related accounting disclosures. Review of Quantitative Finance and Accounting, v. 18, p. 273-291, 2002.

SKINNER, Douglas. Are disclosures about bank derivatives and employee stock options 'value-relevant'? Journal of Accounting and Economics, v. 22, p. 393-405, 1996.

STIGLER, George. The theory of economic regulation. Bell Journal of Economics and Management Science, v. 2, p. 3-21, 1971.

STIGLITZ, Joseph. Information and capital markets. National Bureau of Economic Research - Working Paper $\mathrm{n}^{\circ}$. 678. Social Science Research Network. Disponível em: <wWw.ssrn.com>. Maio, 1981. Acesso em: 11 Setembro 2008.

VALOR ECONÔMICO ONLINE. Derivativos levam Sadia a prejuízo de R\$ 2,48 bilhões em 2008. Publicado em 27 de Março de 2009. Disponível em <http://www.valoronline.com.br>. Acesso em: 1 abr.2009.

VALOR ECONÔMICO ONLINE. Fasb flexibiliza regra para marcação a mercado de ativos. Publicado em 2 de Abril de 2009. Disponível em <http://www.valoronline.com.br>. Acesso em: 3 abr. 2009.

VALOR ECONÔMICO ONLINE. Sensibilidade obrigatória. Publicado em 4 de Dezembro de 2008. Disponível em <http: / /www.valoronline.com.br>. Acesso em: 7 fev. 2009.

VERRECCHIA, Robert. Essays on disclosure. Journal of Accounting and Economics, v. 22, p. 97-180, 2001.

WEIL, David. The benefits and costs of transparency: A model of disclosure based regulation. Social Science Research Network. Disponível em: <www.ssrn.com>. Julho, 2002. Acesso em: 22 ago. 2008.

YAMAMOTO, Marina; SALOTTI, Bruno. Informação contábil: Estudos sobre sua divulgação no mercado de capitais. São Paulo: Atlas, 2006. 


\section{ENDEREÇO DOS AUTORES}

Faculdade de Economia, Administração e Contabilidade

Universidade de São Paulo

Avenida Professor Luciano Gualberto, 908 - Cidade Universitária

Sao Paulo, SP - Brasil

05508-900 